\title{
BAR VERSUS RESILIENT STUD ANCHORS USED FOR IMMEDIATELY LOADED 2 IMPLANTS ASSISTING OVERDENTURES IN PATIENTS WITH HISTORY OF PERIODONTITIS. ONE-YEAR RANDOMIZED CONTROLLED CLINICAL STUDY
}

\author{
Ramy Moustafa Moustafa Ali*, Khaled Mahmoud Selim** and Shaimaa Saieed Nasr***
}

\begin{abstract}
Aim: This randomized controlled study aimed to evaluate clinical outcomes of bar versus resilient stud (locator) anchors used for immediately loaded 2 implants assisting overdentures in patients with history of periodontitis
\end{abstract}

Materials and methods: Twelve completely edentulous patients with a history of chronic periodontitis were randomly classified into 2 groups; Group 1 (locator group); included six participants who received resilient stud (Locator) attachments for overdentures. Group 2 (bar group); included six participants who received bar attachments for overdentures. All patients received 2 implants in the cuspid regions of the mandible using computer guided flapless surgical approach and the implants were immediately loaded with overdentures. Clinical outcomes (implant survival, plaque scores, gingival scores, probing depth, stability of implants, width of keratinized mucosa, and crestal bone loss) were measured at overdenture insertion, 6 and 12 months later.

Results: Plaque and gingival indices, pocket depth, and crestal bone loss increased significantly with time in both groups. Implant stability significantly decreased in locator group and significantly increased with bar group with advance of time. Keratinized mucosal width significantly diminished with time for both attachments. Bar group recorded significant higher plaque and gingival indices, and stability of implants than locator group. On the other hand, Locator group recorded recoded significant higher marginal bone loss than bar group.

Conclusion: Within the limits of this study, Bar attachments are recommended to assist overdentures to immediate loaded implants in subjects with history of periodontitis. However, it is accompanied by increased plaque and gingival scores than Locator attachment.

KEYWORDS : Chronic periodontitis, Bar attachment, Locators.

\footnotetext{
* Lecturer, Department of Removable Prosthodontics, Faculty of Dentistry, Fayoum University, Egypt.

** Lecturer, Department of Oral Medicine and Periodontology, Faculty of Dentistry, Cairo University, Egypt.

*** Lecturer, Department of Oral Medicine and Periodontology, Faculty of Dentistry, Fayoum University, Egypt.
} 


\section{INTRODUCTION}

Periodontitis is one of the major factors for loss of natural teeth and consequently the patients become edentulous and need implant rehabilitation ${ }^{1}$. For completely edentulous patients due to chronic periodontitis, implant supported prosthesis is essential to maintain comfort, chewing, esthetic restoration of natural teeth ${ }^{2}$. Patients with remaining natural teeth who had a history of periodontitis was found to have an inflammation at implant site that may lead to peri-implantitis ${ }^{3,4}$ due to transmission of periodontal pathogens from the teeth to the implant ${ }^{5}$. Many reports showed that implants can be inserted with success in periodontally affected participants but with reduced survival rates than in un-compromised subjects ${ }^{2}$. There is a conflict in the studies with regard to the effect of periodontitis on implant success and survival. Several studies reported that patients with history of periodontitis had increased risk of peri-implantitis that would result in implant failure ${ }^{5-8}$. Other studies reported no significant difference in implant survival rate in patients with and without a history of periodontitis $6,9,10$

In patients with history of periodontal disease, the implant failure may be exacerbated by other confounding factors such as smoking, supportive periodontal therapy and implant surface roughness 9 . Although the use of implant supported fixed restoration providing a high degree of mastication and discomfort, it requires frequent maintenance ${ }^{11}$, 12 and can complicate oral hygiene, especially for patients with a history of periodontal disease or disabilities ${ }^{11}$. Compared to implant fixed restoration, overdentures offers similar retention and function, facilitates oral hygiene and maintenance, and can easily manage esthetic and phonetic problems ${ }^{13}$. The use of implant supported overdentures after extraction of the teeth affected by periodontitis could reduce biomechanical, periodontal, and dentofacial risk, as well as an increase in functional harmony. ${ }^{14}$
There is a consensus in the literature that two implants retaining mandibular overdentures should be the minimum treatment option for edentulous patients ${ }^{15,16}$ as it provides several advantages such as simplicity and cost-effectiveness, improvement of retention and stability of mandibular conventional dentures, increased chewing efficiency and enhancement of patient satisfaction ${ }^{17-19}$. For such overdentures, several attachment systems may be used such as splinted (bar) attachments and non-splinted (Ball anchor, Locator, and magnetic) attachments $^{20}$. Bar attachments provide several advantages such as force distribution between implants, splinting of implants ${ }^{21,22}$, reduced prosthetic complications ${ }^{23}$, and the possibility of use with divergent implants ${ }^{24}$ compared to unsplinted attachments. However, bar and clip attachments need more restorative space, are technically more complex than stud attachments. ${ }^{25}$ The unsplinted attachments provide easier hygiene ${ }^{26}$, are cost effective, and can be used with tapered arches without restriction of tongue space ${ }^{27}$. Among unsplinted attachments, resilient studs (Locators) have a reduced vertical height ${ }^{28}$, different retention values $^{29}$, and can be used with angulated implants ${ }^{29}$.

Immediate loading of dental implants with removable dentures provides immediate restoration of chewing and appearance and speech and avoid the use of unstable conventional dentures during the healing period ${ }^{30}$. However, it may cause increased implant micromotions and interfere with the healing ${ }^{31}$. For immediate loading of implants with overdentures, the of attachment type on peri-implant tissues becomes more important that conventionally loaded implants ${ }^{21}$.

Reviewing the literature, the evaluation of implant overdentures in patients with history of periodontitis are scarce and limited to case reports 2 , 11, 14 in which the authors used telescopic attachments. However, the effect of attachment type on success of the implant overdentures in patients with 
history of periodontitis was not sufficiently evaluated. Consequently, the aim of the present randomized trial was to investigate clinical and radiographic outcomes of Bar versus locator attachments for immediate loaded 2 implants assisting overdentures in subjects with history of periodontitis. The investigators hypothesized that no significant difference will be obtained in clinical outcomes between the 2 attachments.

\section{MATERIALS AND METHODS}

\section{Patient enrollment and study design}

Twelve totally edentulous subjects (6 men and 6 women, average age of $55 \pm 4.5$ years) were included for this randomized controlled trial from the outpatient clinic attending the Prosthodontic department seeking implant treatment for their mandibular edentulous arches or referred from Department of Periodontics, Fayoum University. The inclusion criteria include; 1) All patients had a history of periodontitis before extraction of the teeth. This was verified from patient diagnostic sheets, or by asking the patients about the cause of extraction. 2) all patients were dissatisfied with the retention and stability of their mandibular dentures, 3) All patients had sufficient restorative space [12-15 mm from the mucosa to occlusal surface $]^{32}$ to provide space for both attachments, 4) adequate bone quantity in the interforaminal area of the mandible to receive implants of at least $3.7 \mathrm{~mm}$ in diameter and $11 \mathrm{~mm}$ in length [class III $-\mathrm{V}$ according to Cawood and Howell $\left.{ }^{33}\right], 5$ ) at least 6 months elapsed from the last extraction. The exclusion characters are; smoking, radiation therapy or chemotherapy in the last 2 years, bone metabolic disorders such as diabetes mellitus and hyperparathyroidism, bleeding disorders or other disorders that may contraindicate implant placement. The study plan and the need for frequent recalls were described to all participants, then all participants were asked to sign informed consents. The plane was conducted following the rules of ethics mentioned in the Helsinki statements and the study plane was approved by the ethical committee of the faculty. CONSORT guidelines for randomized controlled trials were followed.

Each participant was given a number and the numbers were entered into an Excel spread sheet. The participants were randomly assigned into two groups after randomization of the patient's number using (RAND) command in excel sheet. Balancing of randomization was performed to ensure equal gender distribution in each group. Randomization and allocation of participants was performed by blinded dentist. Group 1 (locator group); included six participants who received resilient stud (Locator) attachment assisted overdentures. Group 2 (bar group); had six participants who received bar attachment assisted overdentures.

\section{Interventions}

For both groups, new upper and lower conventional dentures were made with balanced occlusion using semi-anatomic acrylic artificial teeth. The patients were allowed to wear the new dentures for at least 2 months to enhance neuromuscular adaptation. Mucosal supported mandibular stereolithographic surgical template was constructed to be used for computer guided flapless implant placement. A dual scanning using cone beam CT (CBCT, Hatfield, PA, USA) was utilized to construct the surgical template. Radiopaque gutta percha markers were attached to the labial and lingual surfaces of the mandibular denture. Patients were asked to wear the maxillary denture and mandibular dentures (with radiopaque markers) in centric occlusion, then the first CBCT scan was performed. The mandibular denture was placed on the tray of the CBCT device and the other scan was made to the mandibular denture alone. The two scans were downloaded to a computer software (OnDemand 3D) and overlapped to form a three-dimensional image of the mandible. Using the software, identification of mental foramen was made, and accurate determining of bone 


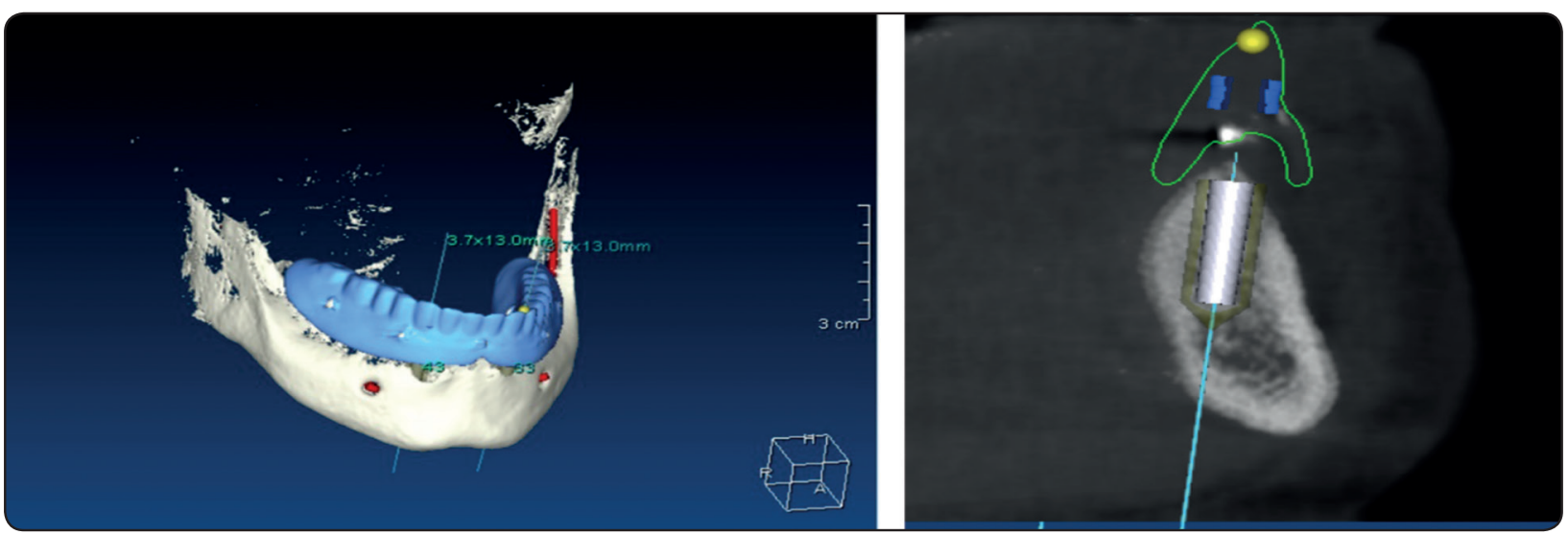

Fig. (1) Planning of implant positions using CBCT scans and OnDemand software.

length and thickness was performed. Moreover, the type of the implant was selected from library, then correct position and orientation of the implants were performed. Implants were positioned in the cuspid areas parallel to each other's. The plan was used to construct a mucosal born stereolithographic surgical guide using laser sintering technology with metal sleeves positioned over implant sites (fig 2).

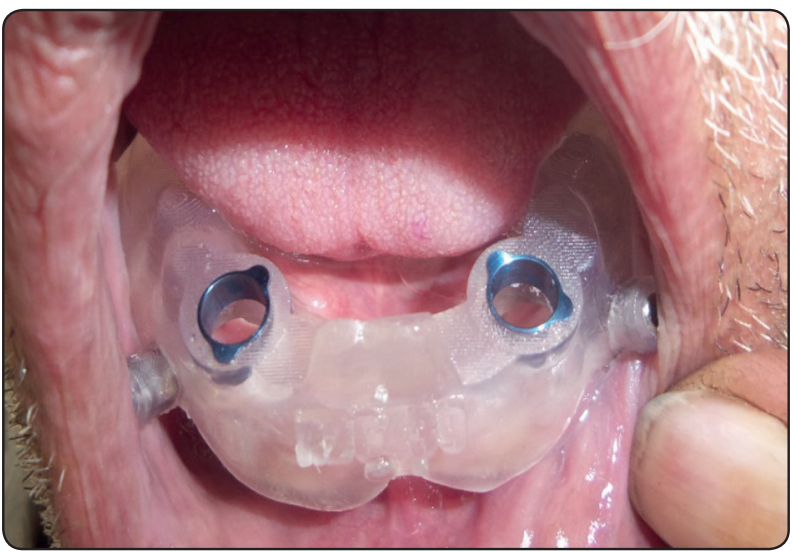

Fig. (2) Mucosal born stereolithographic surgical template

Polyvinyl- siloxane interocclusal record was made over the mandibular surgical guide while the participants wearing the maxillary dentures and close teeth in retruded contact position to be used for fixation of the mandibular surgical guide during surgery. The surgical guide was placed over the mandibular mucosa and anchored to the mandibular bone by drills and anchor fixation screws while the patient bite on the interocclusal record to seat the guide to the mandibular mucosa. Two fixtures (Tiologic, Dentaurum, Germany) were installed in the cuspid areas of the mandible using the flapless surgical approach. Using a tissue punch, 2 circular incisions were performed at canine areas. Implant osteotomes were prepared using the computer guided universal surgical kit (In2Guide) which contain successive metal hand guides (of increasing diameters) that fits accurately the metal sleeves of the surgical guide. The minimum implant insertion torque obtained at surgery should be 35 $\mathrm{Ncm}$ to obtain adequate primary stability required for immediate loading. In case of reduced bone quality, under preparation of the implants site was performed (by removal of the last drill) to obtain adequate primary implant stability.

For group 1 (Locator attachment), locator abutments (Tiologic, Dentaurum, Germany) of adequate mucosal height were threaded to the internal hex of the implants at $25 \mathrm{Ncm}$ torque. Blocking rings were positioned around abutments to avoid contact of acrylic resin to the locator abutments. Metal encapsulator with processing caps were placed over the abutments. The mandibular denture was sufficiently relieved over the metal housing to ensure that there is no contact between the housing and the dentures, and the housing were 
picked up to the dentures using self-cure resin while the participant holding the dentures in retruded contact position. Black processing inserts were replaced with pink nylon inserts (light retention).

For group 2 (bar attachment), long transfer copings were threaded into the internal hex of the implants and splinted with composite resin to avoid accidental movement during impression making. Open tray impression was performed. Light consistency rubber base impression (Aquasil, DENTSPLY, USA) was loaded around the transfer coping, and plastic tray with perforation over the impression posts was loaded with putty material to complete the impression. Implant analogs were threaded to the impression posts and the impression was poured. Bar abutments of adequate mucosal height were threaded to the analogues, and the plastic caps of bar abutments were connected with a resin pattern of Dolder bar joint (Tiologic, Dentaurum, Germany). The resin bar was casted in cobalt-chromium alloy and tried in for passivity. Bar abutments were screwed to the internal hex of the implants at $25 \mathrm{Ncm}$ torque and the bar was screwed to bar abutments at $20 \mathrm{Ncm}$ torque. Titanium sleeve with its spacer was placed over the bar (the sleeve contacts the sides of the bar only). The mandibular denture was sufficiently relieved over the bar to ensure that there is no contact between the bar or bar abutments with the dentures, and the titanium sleeve was picked up to the overdentures using

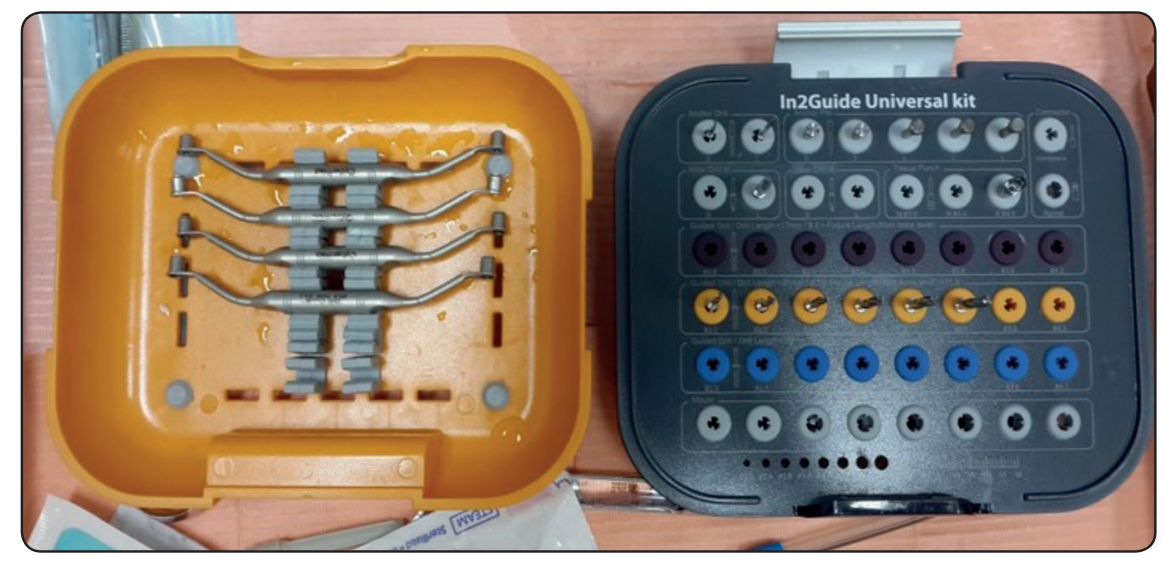

Fig. (3) Computer guided universal surgical kit (In2Guide)

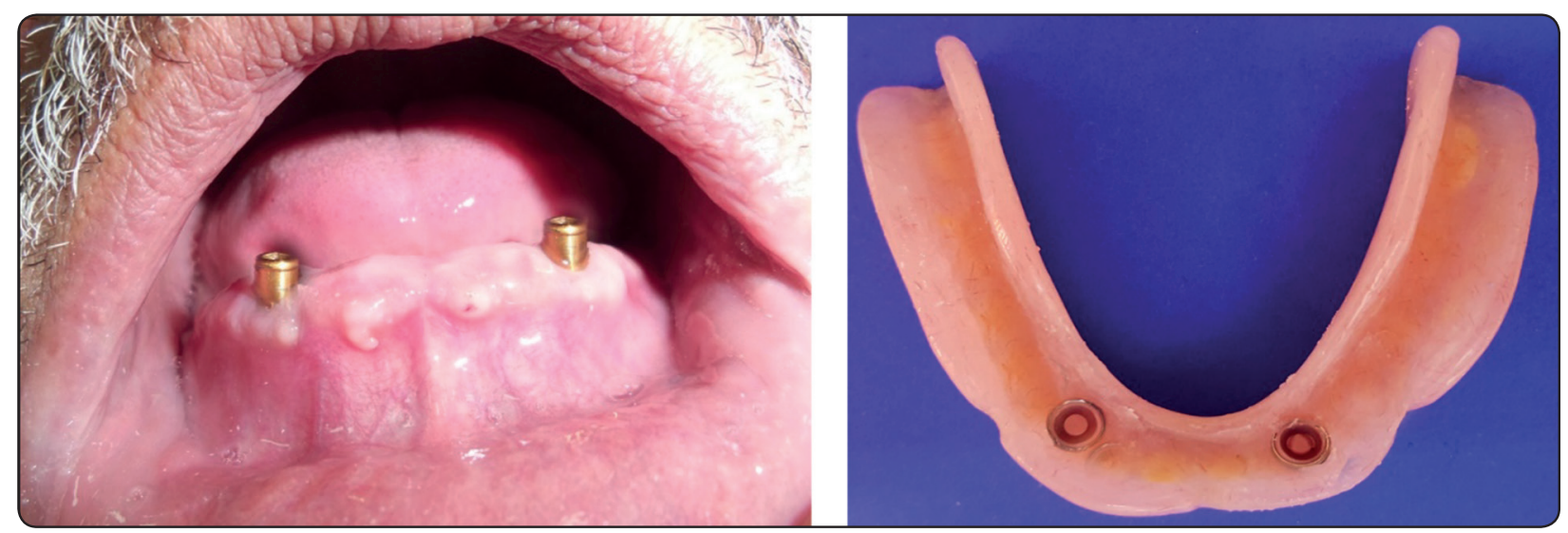

Fig. (4) Locator attachment group; a) Locator abutments screwed to the implants, b) Locator metal housing picked up to the fitting surface of mandibular overdentures 
autopolymerized resin while the participant holding the dentures in retruded contact position. The overdentures were delivered to the patients after 3 days of implant placement.

For both groups necessary occlusal adjustments were performed to ensure homogenous occlusal contact in centric and eccentric relations. All prosthetic procedures were performed by the same prosthodontist. Postoperative medications included Chlorhexidine digluconate $0.2 \%$ mouth wash, antibiotic (Amoxicillin and clavulanic acid) twice/ daily and analgesics (ibuprofen $600 \mathrm{mg} / 8$ hours) were prescribed for 7 days after surgery. The patients were informed to maintain soft diet and adequately clean the surgical site and the prosthesis. Recall appointments were scheduled every 3 months for data collection

\section{Clinical outcomes of the study}

Implant success rate was calculated using the criteria proposed by Albrektsson et al..$^{34}$ which include; Absence of implant mobility; absence of pain, foreign body sensation and/or dysaesthesia), absence of peri-implantitis and suppuration, absence of radiolucency around the implants and vertical bone resorption was not more than $1.5 \mathrm{~mm}$ in the first year. Implant was considered survived if it fulfills function, and does not require removal. Plaque index was measured according to Mombelli et al. ${ }^{35}$ : score $0=$ no plaque, score $1=$ plaque detected by a probe, score $2=$ plaque seen by naked eye, score $3=$ a lot of soft matter. Gingival index was measured using Loe and silness ${ }^{36}$ scores: score $0=$ no bleeding, score $1=$ pinpoint bleeding, score $2=$ linear bleeding, score 3 =profuse bleeding. Pocket depth was measured by plastic periodontal probe
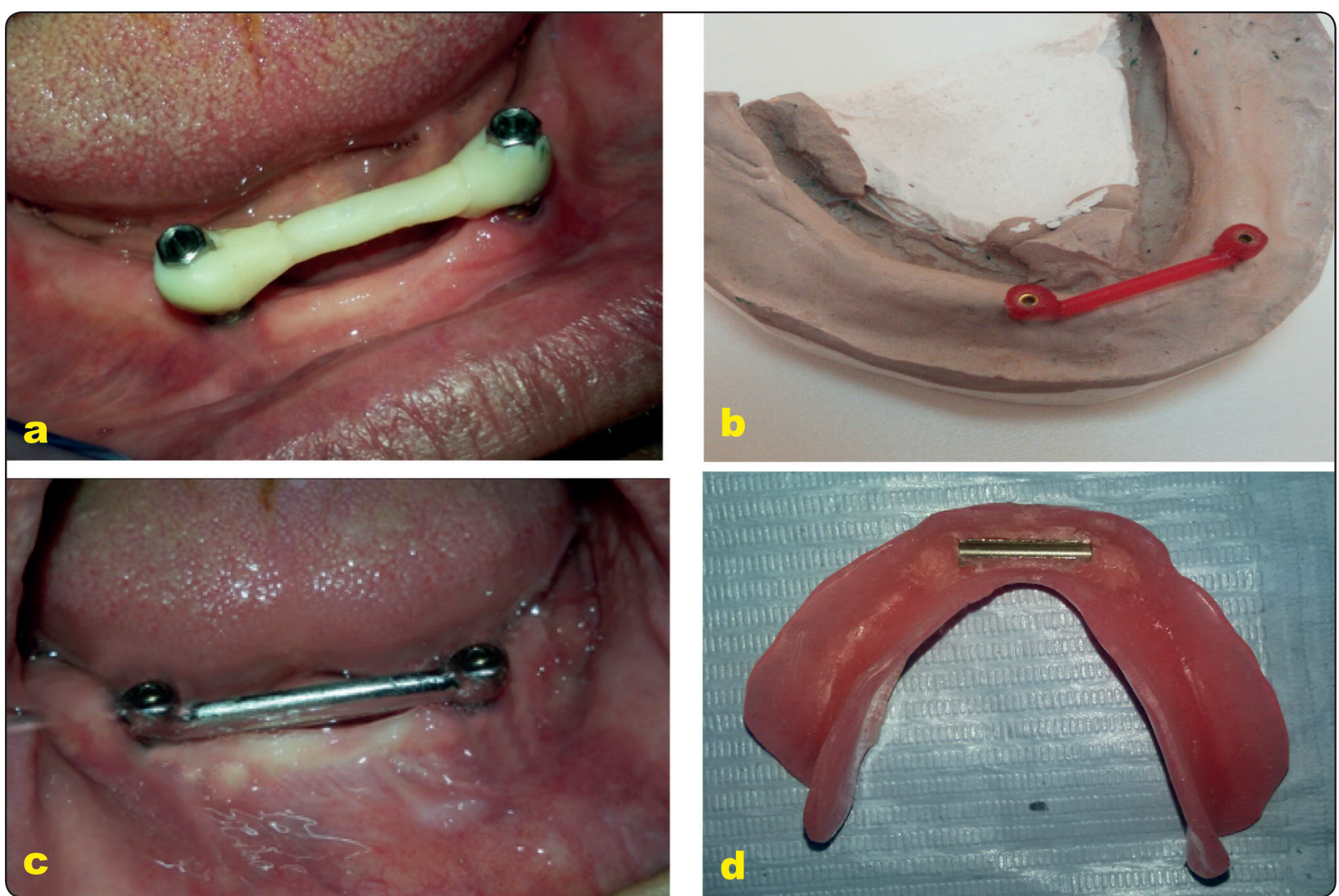

Fig. (5) Bar attachment group; a) splinting the transfer copings using composite resin, b) the resin bar attached to plastic pattern of bar abutment, c) cast bar try-in in patients' mouth, d) the titanium sleeve picked up to the fitting surface of the denture 
which inserted in the peri-implant sulcus to measure the distance between gingival margin and the most apical probing depth. Plaque index, Gingival Index, pocket depth were evaluated at mesial, distal, buccal, and lingual surfaces. Implant stability was measured by using resonance frequency analysis (Osstell ${ }^{\mathrm{TM}}$, Gothenburg, Sweden) and expressed with implant stability quotient ${ }^{37,38}$. The attachments we removed from the implants, and the SmartPeg specific to the implants system was attached to the implants, then the handpiece of the Osstell device was held perpendicularly to the SmartPeg at the buccal surface of the implants. Three measurements were performed for each implant, and the mean was subjected to statistical analysis. The width of keratinized mucosa around each implant was measured in $\mathrm{mm}$ using a graduated periodontal probe as the distance between the gingival border to the mucogingival junction ${ }^{39}$.

Crestal bone loss was measured at mesial, distal, buccal, and lingual surfaces of each implant using CBCT (i- CAT Vision, Hatfield, PA, USA). For standardization of exposure conditions, all images performed with the same acquisition time (14.7 second), voxel size and slice thickness. In the axial window of the CBCT software (OnDemand3DApp), a panoramic curve was made to bisect each implant mesiodistally from the occlusal view. The images were reconstructed by the software in the crosssurface sectional image view for each implant.
Vertical bone height was evaluated at the panoramic window of the software to measure bone height changes at mesial and distal surface of each implant (fig. 6a). Vertical bone height was evaluated at cross surface sectional image to measure bone height changes at buccal and lingual surfaces of each implant (fig. 6b). Marginal bone loss at all surfaces was estimated, where the distance from implant abutment junction to the bone contact with implant was measured using the ruler measure tool of the software to give bone level ${ }^{40}$. Bone loss was calculated by evaluation of bone height changes from base line to 3 months, 6 months and 12 months. The bone loss measurement for mesial, distal, buccal and lingual surfaces were averaged for all implants and the mean was subjected to statistical analysis.

All parameters were measured on patient level at insertion (baseline), 3 months, 6 months, and 12 months later.

\section{Statistical analysis}

Data was analyzed with SPSS program version 25 (SPSS Inc., Chicago, IL, USA). The normal distribution of data was verified by Shapiro wilk test. Life table analysis was used to calculate cumulative implant survival and the difference in implant survival between groups was calculated with Log rank test. Friedman test was used to compare plaque and gingival scores between different time

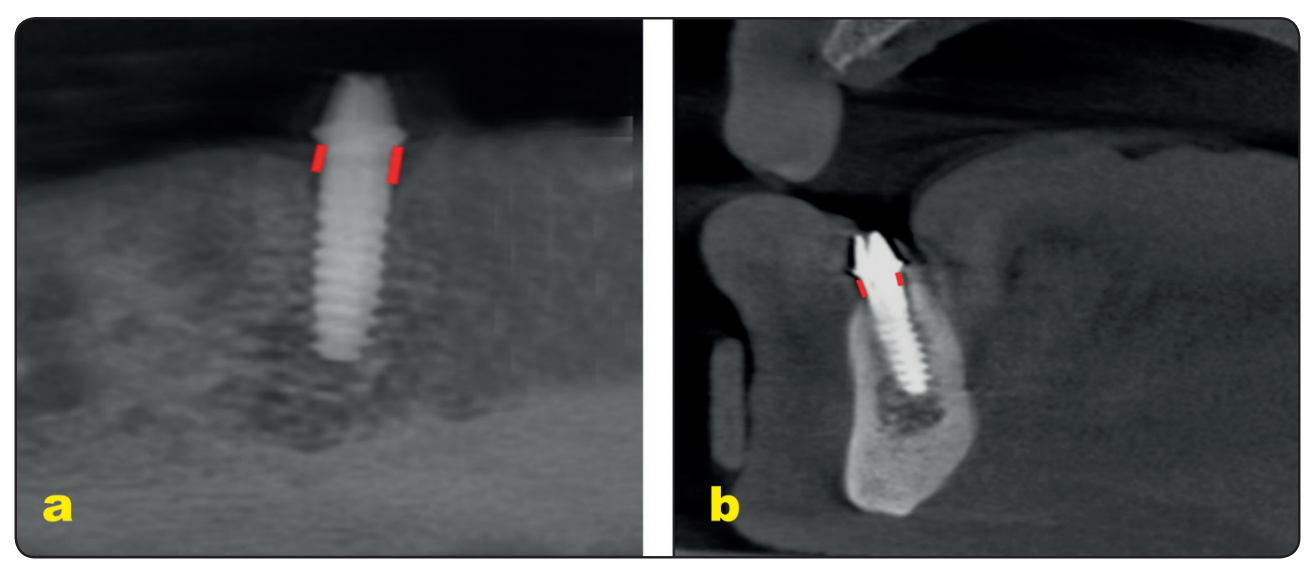

Fig. (6) Measurement of crestal bone height; a) in panoramic images (at mesial and distal surface of each implant), b) in cross sectional images (at buccal and lingual surfaces) 
intervals, and Wilcoxon test was used to test significant difference between each 2 intervals. Comparison between groups was made by the non-parametric Mann- Whitney test. Repeated measures ANOVA was utilized to compare probing depth, stability of implants, keratinized mucosal width, and crestal bone loss between observation times and groups followed by Bonferroni test for multiple comparisons. $\mathrm{P}<.05$ was considered significant.

\section{RESULTS}

No patient dropout occurred. All participants attended the follow-up appointments. Life table analysis of cumulative survival rate of locator and bar groups over 12 months based on 3-months interval periods is presented in table 1. Two implants failed in the locator group 3 months after implant loading, yielding a cumulative survival rate of $94 \%$. No failures were detected for bar group and the cumulative survival was $100 \%$. There was a significant difference in survival rate between groups. The bar group recorded significant implant survival rate than locator group ( $\log$ rank test, $\mathrm{p}=.044)$. The two failed implants in the locator group belonged to the same patient was excluded from the study. The implant failures occurred as a result of implant overloading and to the implants were associated with mobility and crestal bone loss without implant suppuration. The study was conducted according to the intention to treat principal, therefore the data of the rest of the patients in the locator group we are included in the analysis.

Plaque and gingival indices for locator and bar groups at different observation times is presented in table 2. Plaque and gingival indices increased significantly between observation times in both groups. For locator group, plaque index significantly increased from baseline to three months, however no significant difference in plaque scores between 3, 6 and 12 months was observed. For bar group, plaque index increased significantly from baseline to three months, then increased significantly from 3 months to 6 months, however no difference in plaque between 6 months and 12 months was observed. At baseline, no difference in plaque between groups was detected. Bar group had significant higher plaque scores than locator groups at all other observation times. Gingival

TABLE (1) Life table analysis of cumulative survival rate of locator and bar groups over 12 months based on 3-months interval periods

\begin{tabular}{|c|c|c|c|c|c|c|c|}
\hline Group & $\begin{array}{c}\text { Interval } \\
\text { Start Time }\end{array}$ & $\begin{array}{l}\text { Number } \\
\text { Entering } \\
\text { Interval }\end{array}$ & $\begin{array}{c}\text { Number } \\
\text { Withdrawing } \\
\text { during Interval }\end{array}$ & $\begin{array}{l}\text { Number } \\
\text { Exposed to } \\
\text { Risk }\end{array}$ & $\begin{array}{l}\text { Number of } \\
\text { Terminal } \\
\text { Events }\end{array}$ & $\begin{array}{c}\text { Proportion } \\
\text { Surviving }\end{array}$ & $\begin{array}{c}\text { Cumulative } \\
\text { Proportion } \\
\text { Surviving at End } \\
\text { of Interval }\end{array}$ \\
\hline \multirow{5}{*}{ Locator } & 0 & 48.00 & 10.00 & 43.00 & 2.00 & .05 & .95 \\
\hline & 3 & 36.00 & 10.00 & 31.00 & 2.00 & .06 & .94 \\
\hline & 6 & 24.00 & 12.00 & 18.00 & .00 & .00 & 1.00 \\
\hline & 9 & 12.00 & .00 & 12.00 & .00 & .00 & 1.00 \\
\hline & 12 & 12.00 & 12.00 & 6.00 & .00 & .00 & 1.00 \\
\hline \multirow{5}{*}{ Bar } & 0 & 48.00 & 12.00 & 42.00 & .00 & .00 & 1.00 \\
\hline & 3 & 36.00 & 12.00 & 30.00 & .00 & .00 & 1.00 \\
\hline & 6 & 24.00 & 12.00 & 18.00 & .00 & .00 & 1.00 \\
\hline & 9 & 12.00 & .00 & 12.00 & .00 & .00 & 1.00 \\
\hline & 12 & 12.00 & 12.00 & 6.00 & .00 & .00 & 1.00 \\
\hline
\end{tabular}


scores increased with significant difference as time progress for both groups. For both groups, gingival scores increased from baseline to 3 months, then increased significantly from 3 months to 6 months, and no significant difference in gingival scores was detected between 6 and 12 months. At baseline no significant difference in gingival scores was noted between groups. Bar group had higher gingival scores than locator at all other time intervals.

Comparison of probing depth, stability of implants, keratinized mucosal widths, and crestal bone resorption between locator and bar groups and between different time intervals is shown in table 3. Probing depth increased with time in both groups. For both groups, pocket depth increased significantly from baseline to 3 months, then significantly increased from 3 months to 6 months and no difference in pocket depth was observed between 6 and 12 months. No significant difference in pocket depth was observed between groups at all observation times. Implant stability significantly differs between observation times in both groups. For locator group, implant stability significantly decreased from baseline to 3 months and stability of the implants did not differ between 3, 6 and 12 months. For bar group, implant stability significantly increased from baseline to 3 months and no difference in implant stability was noted between 3, 6 and 12 months. At baseline, implant stability did not differ between groups. Bar group showed significant higher implant stability than locator group at all other time intervals.

Keratinized mucosal width reduced significantly with advance of time for both groups. For both groups width of keratinized mucosa decreased significantly from baseline to 3 months, then decreased significantly from 3 months to 6 months, and no difference was noted between 6 and 12 months. No difference in keratinized mucosa was observed between attachments. Crestal bone loss increased with time for both attachments. For both groups, bone loss significantly decreased from 3 months to 6 months, then significantly decreased from 6 months to 12 months. Locators showed higher crestal bone resorption than bar at all time intervals.

TABLE (2) Plaque and gingival indices for locator and bar groups at different observation times

\begin{tabular}{|c|c|c|c|c|c|}
\hline & $\begin{array}{c}\text { Baseline } \\
\text { Median } \\
\text { (mini-maxi) }\end{array}$ & $\begin{array}{c}3 \text { months } \\
\text { Median } \\
\text { (mini-maxi) }\end{array}$ & $\begin{array}{c}6 \text { months } \\
\text { Median } \\
\text { (mini-maxi) }\end{array}$ & $\begin{array}{c}12 \text { months } \\
\text { Median } \\
\text { (mini-maxi) }\end{array}$ & $\begin{array}{r}\text { Freidman } \\
\text { (p value) }\end{array}$ \\
\hline & \multicolumn{5}{|c|}{ Plaque index } \\
\hline Locator & $\begin{array}{c}.00 \mathrm{a} \\
(.00-.00) \\
\end{array}$ & $\begin{array}{c}.5 b \\
(.00-1.0) \\
\end{array}$ & $\begin{array}{c}.5 \mathrm{~b} \\
(0.25-1.0) \\
\end{array}$ & $\begin{array}{c}.5 \mathrm{~b} \\
(0.25-1.0) \\
\end{array}$ & $.034 *$ \\
\hline Bar & $\begin{array}{c}.00 \mathrm{a} \\
(.00-.00)\end{array}$ & $\begin{array}{c}1.25 \mathrm{~b} \\
(1.00-2.00) \\
\end{array}$ & $\begin{array}{c}2.00 \mathrm{c} \\
(1.00-3.00) \\
\end{array}$ & $\begin{array}{c}2.00 \mathrm{c} \\
(1.00-3.00) \\
\end{array}$ & $<.001^{*}$ \\
\hline \multirow[t]{2}{*}{$\begin{array}{c}\text { Mann-Whitney } \\
\text { (p value) }\end{array}$} & 1.00 & $.008 *$ & $.001^{*}$ & $.001 *$ & \\
\hline & \multicolumn{5}{|c|}{ Gingival index } \\
\hline Locator & $\begin{array}{c}.25 \mathrm{a} \\
(.00-.50) \\
\end{array}$ & $\begin{array}{c}.50 \mathrm{~b} \\
(.00-1.00) \\
\end{array}$ & $\begin{array}{c}1.00 \mathrm{c} \\
(.00-1.50)\end{array}$ & $\begin{array}{c}1.00 \mathrm{c} \\
(.00-1.5)\end{array}$ & $.032 *$ \\
\hline Bar & $\begin{array}{c}.30 \mathrm{a} \\
(.00-.50) \\
\end{array}$ & $\begin{array}{c}1.00 \mathrm{~b} \\
(1.0-1.5)\end{array}$ & $\begin{array}{c}1.5 \mathrm{c} \\
(1.00-2.00) \\
\end{array}$ & $\begin{array}{c}1.5 \mathrm{c} \\
(1.00-2.00) \\
\end{array}$ & $.037 *$ \\
\hline $\begin{array}{c}\text { Mann-Whitney } \\
\text { (p value) }\end{array}$ & 1.00 & $.001 *$ & $.003 *$ & $.004 *$ & \\
\hline
\end{tabular}

mini; minimum, maxi, maximum, *p is significant at .05. Different letters demonstrate significant difference between each 2 time intervals (Wilcon test, $p<.05$ ), while similar letters show no difference 
TABLE (3) Comparison of probing depth, stability of implants, keratinized mucosal widths, and crestal bone resorption between locator and bar groups and between different time intervals

\begin{tabular}{|c|c|c|c|c|c|}
\hline & $\begin{array}{c}\text { Baseline } \\
\text { mean } \pm \text { SD }\end{array}$ & $\begin{array}{l}3 \text { months } \\
\text { mean } \pm \text { SD }\end{array}$ & $\begin{array}{l}6 \text { months } \\
\text { mean } \pm \text { SD }\end{array}$ & $\begin{array}{l}12 \text { months } \\
\text { mean } \pm \text { SD }\end{array}$ & $\begin{array}{c}\text { Repeated ANOVA } \\
\text { (p value) }\end{array}$ \\
\hline & \multicolumn{5}{|c|}{ Pocket depth } \\
\hline Locator & $0.9 \pm .25 \mathrm{a}$ & $1.2 \pm .29 \mathrm{~b}$ & $1.45 \pm .30 \mathrm{c}$ & $1.40 \pm .41 \mathrm{c}$ & $.003 *$ \\
\hline Bar & $1.07 \pm .27 \mathrm{a}$ & $1.30 \pm .28 \mathrm{~b}$ & $1.56 \pm .38 \mathrm{c}$ & $1.51 \pm .48 \mathrm{c}$ & $.005^{*}$ \\
\hline \multirow[t]{2}{*}{ t-test (p value) } & 1.00 & .352 & .123 & .211 & \\
\hline & \multicolumn{5}{|c|}{ Stability of implants } \\
\hline Locator & $63 \pm 3.2 \mathrm{a}$ & $60 \pm 3.4 \mathrm{~b}$ & $61 \pm 3.5 b$ & $62 \pm 3.7 \mathrm{~b}$ & $.011 *$ \\
\hline Bar & $62 \pm 3.5 \mathrm{a}$ & $65 \pm 3.7 \mathrm{~b}$ & $66 \pm 3.6 \mathrm{~b}$ & $65 \pm 3.9 \mathrm{~b}$ & $.017 *$ \\
\hline \multirow[t]{2}{*}{ t-test (p value) } & .654 & $.001 *$ & $.007 *$ & $.014^{*}$ & \\
\hline & \multicolumn{5}{|c|}{ Keratinized mucosa } \\
\hline Locator & $1.7 \pm .40 \mathrm{a}$ & $1.5 \pm .34 \mathrm{~b}$ & $1.4 \pm .40 \mathrm{c}$ & $1.4 \pm .40 \mathrm{c}$ & $.022 *$ \\
\hline Bar & $1.6 \pm .38 \mathrm{a}$ & $1.4 \pm .31 b$ & $1.29 \pm .38 \mathrm{c}$ & $1.3 \pm .38 \mathrm{c}$ & $.014^{*}$ \\
\hline \multirow[t]{2}{*}{ t-test ( $p$ value) } & .158 & .147 & .087 & .368 & \\
\hline & \multicolumn{5}{|c|}{ Crestal bone loss } \\
\hline Locator & - & $0.9 \pm .11 \mathrm{a}$ & $1.2 \pm .31 \mathrm{~b}$ & $1.6 \pm .32 \mathrm{c}$ & $<.001 *$ \\
\hline Bar & - & $0.6 \pm .15 \mathrm{a}$ & $0.9 \pm .30 \mathrm{~b}$ & $1.3 \pm .35 \mathrm{c}$ & $.017 *$ \\
\hline t-test (p value) & & $.001 *$ & $.004 *$ & $.002 *$ & \\
\hline
\end{tabular}

*p is significant at .05. Different letters demonstrate significant difference between each 2 time intervals (Bonferroni, $p<.05)$, while similar letters show no difference

\section{DISCUSSION}

Crestal bone loss was measured using cone beam CT instead of conventional periapical radiography as it provides three-Dimensional information regarding bone resorption at the labial and lingual implant surfaces; in addition to mesial and distal surfaces. Conversely, the periapical films are two dimensional which provides information on mesial and distal bone resorption only. Also Cone beam CT is easily used with edentulous patients that had resorption of the ridge with elevated floor of the mouth which makes periapical radiographs difficult to perform ${ }^{41,42}$. The use of cone beam CT in evaluation of marginal bone resorption was previously described in other studies ${ }^{40,43}$.

In this study, the survival rate of the implants ranged from $94 \%$ to $100 \%$ for locator under both groups respectively. This good survival rate was in line with the results of Gomez et al. ${ }^{44}$ who reported higher implant survival rate in patients with history of periodontitis receiving fixed full arch restoration in edentulous mandible. The authors added that 
the survival rate is comparable to implants placed in patients without history of periodontitis. This high survival rate may be due to the good bone quality in the interforaminal area of the mandible which help to maintain good primary stability of the implants. The $100 \%$ survival rate in the bar group concurred with the results of another study 45 for immediate loaded 2 implants in the edentulous mandible and was significantly higher than the survival rate of locator group. The reduced survival rate for immediately loaded 2 implants with locator attachments was in line with the results of another study $^{46}$. Conversely, Kappel et al. ${ }^{47}$ reported a reduced survival rate $(89.1 \%$ and $93.5 \%$ for the bar and Locator attachments) when used to connect overdentures to immediate loaded 2 implants in the mandible

For both groups; plaque and gingival indices, and probing depth increased significantly from baseline to 6 months. A similar finding was also noted in another study ${ }^{44}$ which reported significant increase in the bleeding indices and pocket depth from base line to 8 months in edentulous patients with history of periodontal disease who were rehabilitated by early loaded full-arch fixed screwretained prostheses in the mandible. The increased plaque and gingival scores could be attributed to the presence of microorganisms and oral biofilms that may colonize peri-implant sulcus in patients with history of periodontal diseases such as A. actinomycetemcomitans, Porphyromonas gingivalis, Tannerella forsythia, and Treponema denticola which are associated with increased pocket depth and presence of bleeding during probing ${ }^{48}$. Although teeth extraction significantly reduces these periodontal pathogens, de Waal et al. ${ }^{49}$ reported that A. actinomycetemcomitans and P. gingivalis can persist in the edentulous oral cavity after full-mouth tooth extraction. Another reason for increased plaque and gingival indices with time is the decreased manual dexterity of the included patients due to the relatively old age of the participants and decreased manual cleaning and oral hygiene performance. The bar attachment showed higher plaque and gingival scores than locator attachment. This may be due to the spaces under the bar, and the unobturated areas in the denture around the bar which enhance plaque accumulation and retention and complicate oral hygiene procedures ${ }^{50}$ On the other hand non splinted (Locator) attachments are more hygienic and self-cleansing ${ }^{51}$. A similar finding was observed in another study comparing the effect of bars and locators attachments for mandibular overdentures in patients without history of periodontitis ${ }^{52}$. The authors reported that hygienic maintenance is more complicated around bars when compared with unsplinted locator abutments.

The probing depth in this study did not exceed $1.51 \pm .48 \mathrm{~mm}$ in both groups. A similar value (1.66 \pm 0.53 ) was obtained for implants inserted in patients with history of periodontitis to support a fixed full arch prosthesis in the mandible. The pocket depth increased significantly with time in both groups. This may be due to the elevated crestal bone resorption with time and the periimplant mucosal enlargement. However, the was no difference in pocket depth between groups was detected. It was expected that pocket depth in the bar group would be higher than locator group due to increased gingival inflammation and proliferation around abutments. However, the increased marginal bone loss in the locator group could be the reason for elevated probing depth in this group.

Implant stability significantly decreased from base line to 3 months in locator group. This could be attributed to decreased bone-implant contact caused by remodeling together with the increased implant micromotions applied to the locator attachments as these attachments are non-splinted and have dual frictional flanges. These micromotions could contribute to reduced bone to implant contact in the critical healing period. However, implant stability reached a plateau after 3 months. A similar finding 
was observed in another study for immediate loaded implants with locator attachment ${ }^{46}$. The implant stability significantly increased with bar group from base line to 3 months; also bar group recorded significant higher implant stability than locator group. This could be attributed to the splinting effect of the bar attachments which reduced load and distribute forces over the 2-implant creating more surface area, and consequently decrease implant micromotions and increase bone to implant contact in the healing stage (first 3 months) after immediate loading of the implants..$^{53}$

For both groups keratinized mucosa significantly reduced with time. A similar finding was noted in another study ${ }^{54}$ and could be attributed to elevated crestal bone resorption, probing depth and mucosal recession that occurred with time. Moreover, the mucosal recession may occur due to stripping of mucosa by the labial flange of the denture during insertion and removal ${ }^{54}$. However, no difference in keratinized mucosa between attachments was noted.

Marginal bone loss was $1.6 \pm .32$ for locator group and $1.3 \pm .35$ for bar groups after 12 months. These values of crestal bone loss were higher than the usual level of bone resorption reported in the previous studies for normal patients (without periodontitis) which does not exceed $1.2 \mathrm{~mm}$ in the first year ${ }^{34}$. This finding agreed with the results of another study ${ }^{55}$ in which the authors showed higher marginal bone loss in dentate patients with history of periodontitis and compared to periodontally healthy patients. The bone loss values in this study for both groups ranged between $1.3 \mathrm{~mm}$ and 1.6 $\mathrm{mm}$ after one year. A similar range of crestal bone loss $(1.45$ to $1.75 \mathrm{~mm})$ was obtained for implants supporting mandibular fixed full arch hybrid prosthesis in patients with history of periodontitis. For both groups crestal bone loss significantly increased with passage of time. The time dependent bone loss was not surprising and could be attributed to bone response to healing process and immediate loading protocol $^{56}$. Similarly, Elsyad, et al. ${ }^{46,57}$ reported increased bone loss with advance of time in patients received immediate loaded 2 implants retaining mandibular overdentures with ball and locator attachments compared to conventional loading. The increased implant micromotions caused by immediate loading of the critical healing may negatively affect the bone to implant contact and resulted in greater bone turnover ${ }^{53}$, consequently bone loss increased with time. It is interesting to find that bar attachment showed significantly lower crestal bone loss than locator attachments. This may be attributed to the splinting effect of the bar attachment which minimizes the implant micromotions, reduce horizontal and rotational movements on the implants, and transfer axial load to the immediately loaded implants ${ }^{53}$. Moreover, the type of the bar used in this study (Dolder bar joint) contributed significantly to the reduced stresses applied to the implants as the metal sleeve contact the sides of the bar only, with space exist between the top of the bar and the sleeve. This provide vertical resiliency and permit rotational movements, consequently the loads are transferred to the mandibular posterior ridges rather than to the implants as overdenture rotates during mastication. A similar finding was also observed in another study ${ }^{40}$ in which the authors reported reduced marginal bone loss around immediately loaded implants was bar attachments compared to ball attachments. In contrast, the solitary locator anchors are subjected to higher forces during the early healing of immediately loaded implants ${ }^{58}$. Moreover, the dual retention mechanism of locator attachment provides increased retention forces from the implants, increased friction, and limit lateral and hinge movement ${ }^{59}$. This may transmit more moment load to the implants. In agreement with this explanation, the investigators in another vitro study ${ }^{60}$ noted increased stresses around implants with locators compared to bars for mandibular overdenture. 


\section{CONCLUSION}

Within the limits of this short term randomized clinical study, bar attachments are recommended to connect overdentures to immediate loaded implants in patients with history of periodontitis as it was associated with increased implant survival rate, implant stability and decreased crestal bone loss compared to locator anchors. However, it was associated with increased plaque and gingival indices scores than locator attachment.

\section{REFERENCES}

1. Do TA, Le HS, Shen YW, Huang HL, Fuh LJ. Risk Factors related to Late Failure of Dental Implant-A Systematic Review of Recent Studies. Int J Environ Res Public Health. 2020;17.

2. Thone-Muhling M, Peleska B, Gockel F, Lotzmann U, Mengel R. Template-guided flapless implant insertion and prosthetic rehabilitation with telescopic crowns in a patient with treated generalized aggressive periodontitis: a case report. Quintessence Int. 2012;43:179-85.

3. Heitz-Mayfield LJ. Peri-implant diseases: diagnosis and risk indicators. J Clin Periodontol. 2008;35:292-304.

4. Jemt T, Karouni M, Abitbol J, Zouiten O, Antoun H. A retrospective study on 1592 consecutively performed operations in one private referral clinic. Part II: Periimplantitis and implant failures. Clin Implant Dent Relat Res. 2017;19:413-22.

5. Karoussis IK, Kotsovilis S, Fourmousis I. A comprehensive and critical review of dental implant prognosis in periodontally compromised partially edentulous patients. Clin Oral Implants Res. 2007;18:669-79.

6. Levin L, Ofec R, Grossmann Y, Anner R. Periodontal disease as a risk for dental implant failure over time: a long-term historical cohort study. J Clin Periodontol. 2011;38:732-7.

7. Quirynen M, Abarca M, Van Assche N, Nevins M, van Steenberghe D. Impact of supportive periodontal therapy and implant surface roughness on implant outcome in patients with a history of periodontitis. J Clin Periodontol. 2007;34:805-15.

8. Van der Weijden GA, van Bemmel KM, Renvert S. Implant therapy in partially edentulous, periodontally compromised patients: a review. J Clin Periodontol. 2005;32:506-11.
9. Vercruyssen M, Quirynen M. Long-term, retrospective evaluation (implant and patient-centred outcome) of the two-implant-supported overdenture in the mandible. Part 2: marginal bone loss. Clin Oral Implants Res. 2010; $21: 466-72$

10. Derks J, Hakansson J, Wennstrom JL, Tomasi C, Larsson $\mathrm{M}$, Berglundh T. Effectiveness of implant therapy analyzed in a Swedish population: early and late implant loss. J Dent Res. 2015;94:44S-51S.

11. Morandi R, Cabral LM, de Moraes M. Implant-supported maxillary denture retained by a telescopic abutment system: A clinical report. J Prosthet Dent. 2017;117:331-4.

12. Tolstunov L. "13-23-30" anatomic approach for maxillary full-arch implant reconstruction: a case report and surgical-prosthetic considerations. J Oral Maxillofac Surg. 2010;68:818-24.

13. Hoffmann O, Beaumont C, Tatakis DN, Zafiropoulos GG. Telescopic crowns as attachments for implant supported restorations: a case series. J Oral Implantol. 2006;32:291-9.

14. McMaster D. Implant-assisted overdenture: a case report. Compend Contin Educ Dent. 2011;32:42-4, 6-7.

15. Feine JS, Carlsson GE, Awad MA, Chehade A, Duncan WJ, Gizani S et al. The McGill Consensus Statement on Overdentures. Montreal, Quebec, Canada. May 24-25, 2002. Int J Prosthodont. 2002;15:413-4.

16. Thomason JM, Feine J, Exley C, Moynihan P, Muller F, Naert I et al. Mandibular two implant-supported overdentures as the first choice standard of care for edentulous patients--the York Consensus Statement. Br Dent J. 2009;207:185-6.

17. MacEntee MI, Walton JN, Glick N. A clinical trial of patient satisfaction and prosthodontic needs with ball and bar attachments for implant-retained complete overdentures: three-year results. J Prosthet Dent. 2005;93:28-37.

18. Meijer HJ, Raghoebar GM, Van 't Hof MA. Comparison of implant-retained mandibular overdentures and conventional complete dentures: a 10-year prospective study of clinical aspects and patient satisfaction. Int J Oral Maxillofac Implants. 2003;18:879-85.

19. Naert I, Alsaadi G, van Steenberghe D, Quirynen M. A 10-year randomized clinical trial on the influence of splinted and unsplinted oral implants retaining mandibular overdentures: peri-implant outcome. Int J Oral Maxillofac Implants. 2004;19:695-702. 
20. Trakas T, Michalakis K, Kang K, Hirayama H. Attachment systems for implant retained overdentures: a literature review. Implant Dent. 2006;15:24-34.

21. Akca K, Akkocaoglu M, Comert A, Tekdemir I, Cehreli MC. Bone strains around immediately loaded implants supporting mandibular overdentures in human cadavers. Int J Oral Maxillofac Implants. 2007;22:101-9.

22. Mericske-Stern R, Piotti M, Sirtes G. 3-D in vivo force measurements on mandibular implants supporting overdentures. A comparative study. Clin Oral Implants Res. 1996;7:387-96

23. Naert I, Gizani S, Vuylsteke M, Van Steenberghe D. A 5-year prospective randomized clinical trial on the influence of splinted and unsplinted oral implants retaining a mandibular overdenture: prosthetic aspects and patient satisfaction. J Oral Rehabil. 1999;26:195-202.

24. Carpentieri JR. Clinical protocol for an overdenture bar prosthesis fabricated with CAD/CAM technology. Pract Proced Aesthet Dent. 2004;16:755-7.

25. Sadowsky SJ. Mandibular implant-retained overdentures: a literature review. J Prosthet Dent. 2001;86:468-73.

26. Gotfredsen K, Holm B. Implant-supported mandibular overdentures retained with ball or bar attachments: a randomized prospective 5-year study. Int J Prosthodont. 2000;13:125-30.

27. Spiekermann H. Implantalogy. In: Rateitschak, K.H. \& Wolf, H.F., eds. Color Atlas of Dental Mediᄀcine. New York: Theme Medical Publishers. 1995.

28. Lee CK, Agar JR. Surgical and prosthetic planning for a two-implant-retained mandibular overdenture: a clinical report. J Prosthet Dent. 2006;95:102-5.

29. Nguyen CT, Masri R, Driscoll CF, Romberg E. The effect of denture cleansing solutions on the retention of pink Locator attachments: an in vitro study. J Prosthodont. 2010;19:226-30.

30. De Bruyn H, Raes S, Ostman PO, Cosyn J. Immediate loading in partially and completely edentulous jaws: a review of the literature with clinical guidelines. Periodontol 2000. 2014;66:153-87.

31. Romanos GE, Nentwig GH. Immediate versus delayed functional loading of implants in the posterior mandible: a 2-year prospective clinical study of 12 consecutive cases. Int J Periodontics Restorative Dent. 2006;26:459-69.

32. Ahuja S, Cagna DR. Defining available restorative space for implant overdentures. J Prosthet Dent. 2010;104:133-6.
33. Cawood JI, Howell RA. A classification of the edentulous jaws. Int J Oral Maxillofac Surg. 1988;17:232-6.

34. Albrektsson T, Zarb G, Worthington P, Eriksson AR. The long-term efficacy of currently used dental implants: a review and proposed criteria of success. Int J Oral Maxillofac Implants. 1986;1:11-25.

35. Mombelli A, van Oosten MA, Schurch E, Jr., Land NP. The microbiota associated with successful or failing osseointegrated titanium implants. Oral Microbiol Immunol. 1987;2:145-51.

36. Loe H, Silness J. Periodontal Disease in Pregnancy. I. Prevalence and Severity. Acta Odontol Scand. 1963; 21:533-51.

37. Meredith N, Alleyne D, Cawley P. Quantitative determination of the stability of the implant-tissue interface using resonance frequency analysis. Clin Oral Implants Res. 1996;7:261-7.

38. Glauser R, Sennerby L, Meredith N, Ree A, Lundgren A, Gottlow $\mathrm{J}$ et al. Resonance frequency analysis of implants subjected to immediate or early functional occlusal loading. Successful vs. failing implants. Clin Oral Implants Res. 2004;15:428-34.

39. Lin GH, Chan HL, Wang HL. The significance of keratinized mucosa on implant health: a systematic review. J Periodontol. 2013;84:1755-67.

40. Elsyad MA, Khirallah AS. Circumferential bone loss around splinted and nonsplinted immediately loaded implants retaining mandibular overdentures: A randomized controlled clinical trial using cone beam computed tomography. J Prosthet Dent. 2016;116 741-8

41. Naitoh M, Hayashi H, Tsukamoto N, Ariji E. Labial bone assessment surrounding dental implant using cone-beam computed tomography: an in vitro study. Clin Oral Implants Res. 2012;23:970-4.

42. Raes F, Renckens L, Aps J, Cosyn J, De Bruyn H. Reliability of circumferential bone level assessment around single implants in healed ridges and extraction sockets using cone beam CT. Clin Implant Dent Relat Res. 2013;15:661-72.

43. Razavi T, Palmer RM, Davies J, Wilson R, Palmer PJ. Accuracy of measuring the cortical bone thickness adjacent to dental implants using cone beam computed tomography. Clin Oral Implants Res. 2010;21:718-25.

44. Gomes JA, Sartori IAM, Able FB, de Oliveira Silva TS, do Nascimento C. Microbiological and clinical outcomes of fixed complete-arch mandibular prostheses supported by 
immediate implants in individuals with history of chronic periodontitis. Clin Oral Implants Res. 2017;28:734-41.

45. Reis R, Nicolau P,Calha N, Messias A, Guerra F. Immediate versus early loading protocols of titanium-zirconium narrow-diameter implants for mandibular overdentures in edentulous patients: 1-year results from a randomized controlled trial. Clin Oral Implants Res. 2019;30:953-61.

46. Elsyad MA, Elsaih EA, Khairallah AS. Marginal bone resorption around immediate and delayed loaded implants supporting a locator-retained mandibular overdenture. A 1-year randomised controlled trial. J Oral Rehabil. 2014;41:608-18.

47. Kappel S, Giannakopoulos NN, Eberhard L, Rammelsberg $\mathrm{P}$, Eiffler C. Immediate Loading of Dental Implants in Edentulous Mandibles by Use of Locator(R) Attachments or Dolder(R) Bars: Two-Year Results from a Prospective Randomized Clinical Study. Clin Implant Dent Relat Res. 2016;18:752-61.

48. Socransky SS, Haffajee AD, Cugini MA, Smith C, Kent RL, Jr. Microbial complexes in subgingival plaque. J Clin Periodontol. 1998;25:134-44.

49. de Waal YC, Winkel EG, Raangs GC, van der Vusse ML, Rossen JW, van Winkelhoff AJ. Changes in oral microflora after full-mouth tooth extraction: a prospective cohort study. J Clin Periodontol. 2014;41:981-9.

50. Elsyad MA, Shoukouki AH. Resilient liner vs. clip attachment effect on peri-implant tissues of bar-implant-retained mandibular overdenture: a 1-year clinical and radiographical study. Clin Oral Implants Res. 2010;21:473-80.

51. Kleis WK, Kammerer PW, Hartmann S, Al-Nawas B, Wagner W. A comparison of three different attachment systems for mandibular two-implant overdentures: oneyear report. Clin Implant Dent Relat Res. 2010;12:209-18.

52. Cordaro L, di Torresanto VM, Petricevic N, Jornet PR, Torsello F. Single unit attachments improve peri-implant soft tissue conditions in mandibular overdentures supported by four implants. Clin Oral Implants Res. 2013;24:536-42.

53. Alfadda SA, Attard NJ, David LA. Five-year clinical results of immediately loaded dental implants using mandibular overdentures. Int J Prosthodont. 2009;22:368-73.

54. ELsyad MA, Denewar BA, Elsaih EA. Clinical and Radiographic Evaluation of Bar, Telescopic, and Locator Attachments for Implant-Stabilized Overdentures in Patients with Mandibular Atrophied Ridges: A Randomized Controlled Clinical Trial. The International journal of oral \& maxillofacial implants. 2018;33:1103-11.

55. Graetz C, El-Sayed KF, Geiken A, Plaumann A, Salzer $\mathrm{S}$, Behrens $\mathrm{E}$ et al. Effect of periodontitis history on implant success: a long-term evaluation during supportive periodontal therapy in a university setting. Clin Oral Investig. 2018;22:235-44.

56. Hohlweg-Majert B, Metzger MC, Kummer T, Schulze D. Morphometric analysis - Cone beam computed tomography to predict bone quality and quantity. J Craniomaxillofac Surg. 2011;39:330-4.

57. Elsyad MA, Al-Mahdy YF, Fouad MM. Marginal bone loss adjacent to conventional and immediate loaded two implants supporting a ball-retained mandibular overdenture: a 3-year randomized clinical trial. Clin Oral Implants Res. 2012;23:496-503.

58. Misch CE, Wang HL, Misch CM, Sharawy M, Lemons J, Judy KW. Rationale for the application of immediate load in implant dentistry: part II. Implant Dent. 2004;13:310-21.

59. Chikunov I, Doan P, Vahidi F. Implant-retained partial overdenture with resilient attachments. J Prosthodont. 2008;17:141-8.

60. Celik G, Uludag B. Photoelastic stress analysis of various retention mechanisms on 3-implant-retained mandibular overdentures. J Prosthet Dent. 2007;97:229-35. 